\title{
THE ICHNOFOSSIL RECORD OF HYMENOPTERAN NESTING BEHAVIOR FROIM MESOZOIC AND CENOZOIC PEDOGENIC AND XYLIC SUBSTRATES: EXAMPLE OF RELATIVE STASIS
}

HASIOTIS*, Stephen. T., Dept. Geological Sciences, University of Colorado, Campus Box 250, Boulder, CO 80309; BOWN, Thomas M., University of Colorado Museum, Geology Section, Campus Box 250, Boulder, CO 80309; KAY, Paul, T., P.O. Box 18848, Denver, CO 80218; DUBIEL, R. F., U.S. Geological Survey, Box 25046, MS 919, Denver, CO 80225; DEMKO, T. M., Dept. Earth Resources, Colorado State Univ., Fort Collins, CO 81123

Ichnofossils of Triassic bee and wasp nests strongly suggest that primitive social behavior in hymenopteran insects evolved more than 110 million years before the rise of angiosperms (flowering plants). Previously, bees and wasps were thought to have evolved in the Early Cretaceous, concomitant with the development of angiosperms. Ichnofossils of organized cell constructions (nests), and groups of cocoons provide striking evidence that bees and wasps inhabited terrestrial ecosystems of the Upper Triassic Chinle Formation in the Petrified Forest National Park, Arizona. By Triassic times (230 million years ago [Ma]), primitive bees and wasps were ecologically diverse, with their fossil nests occurring in both pedogenic and xylic substrates. These traces extend the range of bees and wasps (Hymenoptera: Apocrita) and their nesting behavior by 140 and 155 million years, respectively. The previously recognized oldest fossil evidence of these hymenopterans include a Late Cretaceous (80 Ma) bee in amber (New Jersey), a Late Cretaceous (75 Ma) comb wasp nest (Utah), and Early Cretaceous (116 Ma) fossils of aculeatan stinging wasps (Brazil). The earliest hymenopteran body fossils are sawflies (Xyelidae) from the Late? Triassic of Australia and Russia.

How does one conclude that these traces represent nests of gregarious and primitively-social hymenopterans rather than constructions of other insects like coleopterans (beetles) or by an unknown insect that behaved nearly identical to hymenopterans but that has no known fossil record? The best way to resolve this problem is to: 1) evaluate the architectural and surficial morphologies of known Cenozoic and Mesozoic hymenopteran nests and cocoons to identify the specific behavior that constructed the nests, and 2) scrutinize the architectural and surficial nest morphologies of the Triassic traces and compare them with those of known hymenopteran nests and cocoons. If a pattern of characteristic morphologies indicative of hymenopteran behavior emerges through these comparisons, then the fossil nests were produced by higher taxa of the Hymenoptera rather than a different insect order or an unknown group of insects.

Ichnofossils of bee and wasp nests and cocoons were evaluated from Neogene, Paleogene, and Cretaceous paleosols developed on fluvial and eolian deposits. The cells of the bee nests are flask-shaped (sometimes with a crooked-neck), smooth-walled, 1 to $2 \mathrm{~cm}$ in length, and form clusters of multi-layered rows of cells. The cocoons of wasp nests are spindle-shaped pellets with a thread-like bioglyph on their surfaces; they are 0.5 to $3 \mathrm{~cm}$ in length, and occur in small to large groups. Pre-Quaternary traces are nearly identical to those of extant halictids (semi-social), anthophorids (primivitlely-social), sphecids (gregarious), and pompilid nests, and thus allow direct comparison of the nesting and foraging behavior involved in ancient nest construction.

Evaluation of Triassic cell morphologies and nest configurations, and comparisons to the hymenopteran nests and cocoons, demonstrate that the Triassic nests reflect hymenopteran nesting and foraging behavior. The architecture and surficial morphologies of these earliest hymenopteran nests and their inferred behavior are closely similar to those of their modern representatives; they appear to have developed independent of angiosperm diversification, and have exhibited relative stasis to the present time. Basic patterns in cell construction, nest configuration, and substrate requirements are unchanged. 